\title{
Review
}

\section{Screening and identification of new biomarkers for the control of cervical cancer}

\author{
Mari Uyeda ${ }^{1}$, Mahendran Subramaniann ${ }^{2, *}$ \\ 1 AC Camargo Cancer Center, Department of Radiotherapy of the Hospital, Tamandaré St, 753-Liberdade, \\ São Paulo, Brazil, 01509-020; mariuyedanutri@gmail.com \\ 2 Department of Bioengineering, Department of Computing, Imperial College London, South Kensington \\ Campus, United Kingdom, SW7 2AZ; m.subramanian@imperial.ac.uk \\ * Correspondence: Correspondence to m.subramanian@imperial.ac.uk; Tel.: +44 7922105766
}

Simple Summary: Many women are affected by cervical cancer worldwide and it is almost always related to the human papillomavirus. Screening with traditional tests together with detailed exams that can identify the presence of precancerous lesions or even the existence of cancer are becoming increasingly important in the diagnosis, avoiding countless deaths. In this article, we explore what exists in the literature about these tests for an effective treatment, with a decrease in cancer recurrence. As well as explain ways for the development of biomarkers that are based on the DNA of the virus and how genetic changes can interfere in the diagnosis. As protein changes can be identified through an analytical method used to identify different compounds based on the sample's atomic constitution, called mass spectrometry.

Abstract:

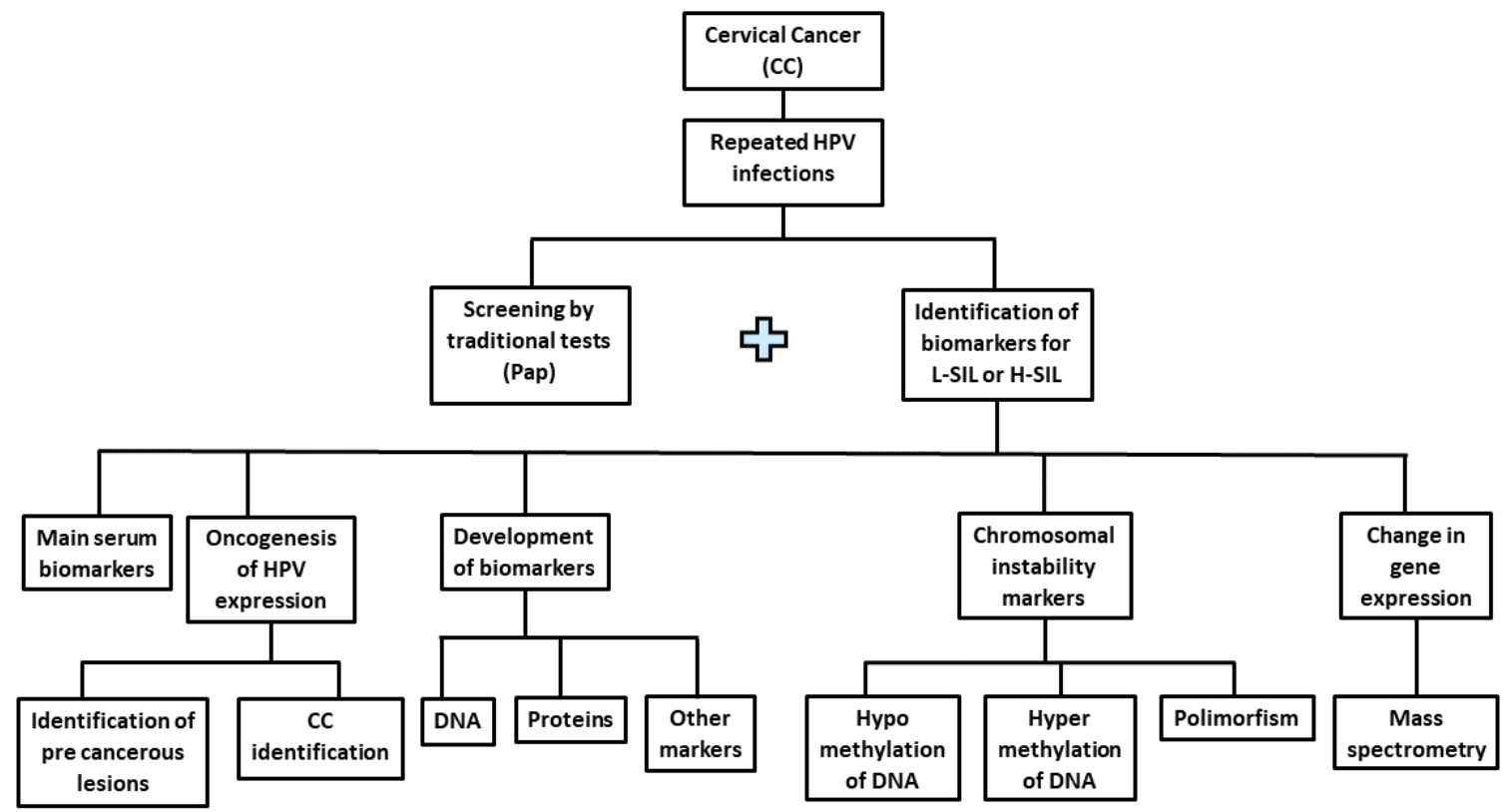

Cervical cancer (CC) is the most common cancer in women worldwide and is almost always associated with repeated infections by human papillomavirus (HPV). Screening by traditional tests associated with biomarker identification techniques for low- or high-grade injuries, are becoming increasingly important in diagnosis and prognosis, avoiding countless deaths. This article explores existing literature on the main serum biomarkers and the identification of biomarkers associated with the oncogenesis of HPV expression in the identification of pre-cancerous lesions and of CC for an effective treatment, with reduction of recurrence, as well as we explain strategies for the development of biomarkers based on DNA, proteins and other markers. We also describe how markers of chromosomal instability host DNA, promoting hypo- or hypermethylation of DNA, as well as polymorphisms and epigenetic events in the p53 gene. Finally, we discuss changes in gene 
expression using cDNA microarray techniques and changes in the expression of proteins and markers identified through mass spectrometry (MS).

Keywords: Cervical cancer, Biomarkers, Human papillomavirus, Pap smear, cervical intraepithelial neoplasia

\section{Introduction}

Cervical cancer (CC) is considered the fourth type of cancer that most commonly affects women worldwide, with an estimated incidence of 569,847 cases and 311,365 deaths, according to the latest Globocan report [1]. CC is almost always caused by repeated infections with human papillomavirus (HPV). Although it has started to show a decline in developed countries, this reality does not yet occur in developing countries, being high among women in about 43 countries [2]. About $85 \%$ of all deaths from CC originate from low-income countries and are 18 times higher than in developed countries [3]. This inconsistency in the mortality rate between developed and developing / underdeveloped countries is due to a lack of awareness, screening programmes, inaccessibility to adequate diagnoses and effective treatment procedures, in addition to greater exposure to the risk factors that lead to the CC. In addition to HPV infection, poor hygiene, smoking, use of oral contraceptives, exposure to diethylstilbestrol and genetic predisposition are particularly common among women of low socioeconomic status [4]. Although HPV infection cannot induce cervical carcinogenesis alone, it is a primary requirement for most cases of CC [5].

Currently, more than 200 different types of HPV are described that infect epithelial cells [6], of which about 40 have tropism in the mucosa tissues. These are further divided into low- and high-risk HPV (L-SIL HPV and H-SIL HPV, respectively), depending on their carcinogenic potential [7]. L-HPV is associated with the development of anogenital warts, while types of H-HPV are associated with cervical intraepithelial neoplasia (CIN) and CC 3 of H-HPV, HPV-16 and 18 are responsible for approximately $70 \%$ of CC cases globally $[8,9]$.

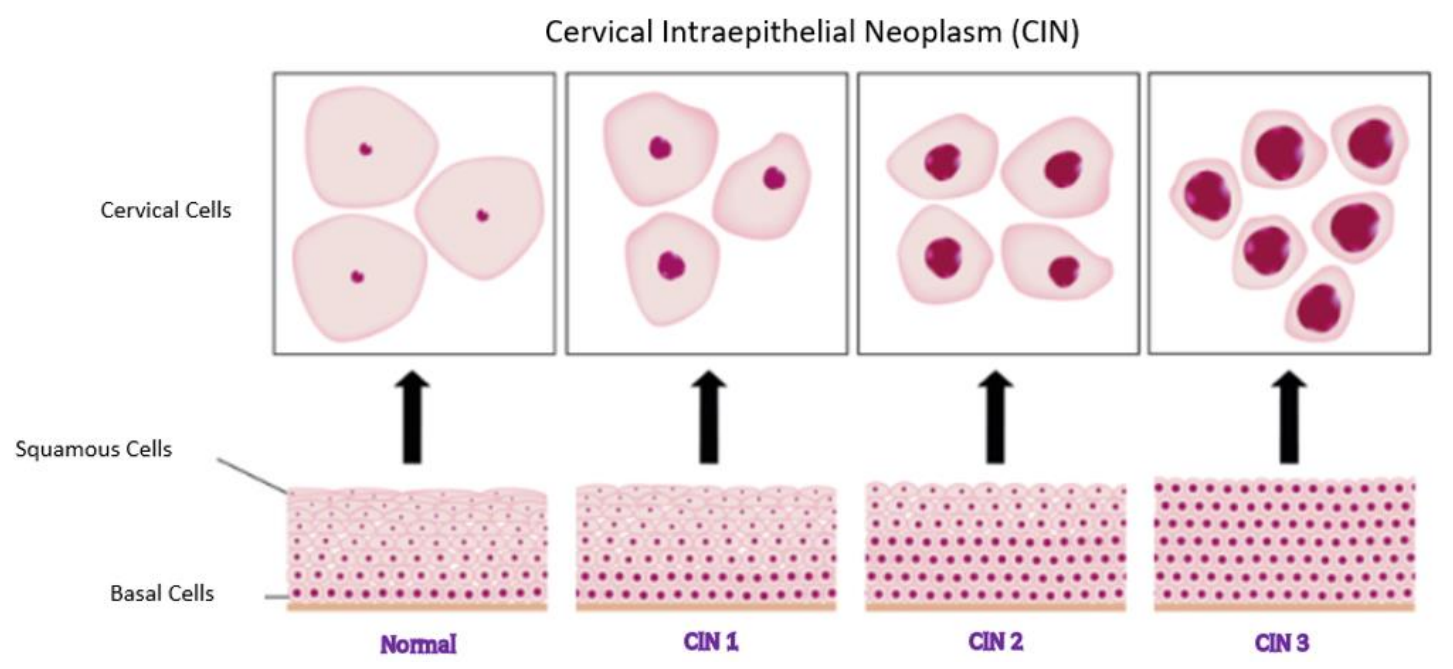

Figure 1 Formation of cervical intraepithelial neoplasia.

\subsection{Pathophysiology}

Cervical adenocarcinoma differs from squamous cell carcinoma in that it begins in the glandular epithelium of the endocervical canal and begins immediately with adenocarcinoma in situ. The time difference between HPV infection and the development of CC is generally 20 years; therefore, rapid progression of CC rarely occurs [10]. Figure 1 shows how the formation of cervical intraepithelial neoplasia occurs. 
The CIN is different, depending on its degree. CIN1 is an L-SIL, where 70 to $80 \%$ of lesions regress spontaneously without treatment or become undetectable [11, 12], reflecting a state of infection and not a stage in the development of the disease. Detection of CIN1 after HPV infection, therefore, does not automatically represent disease progression. Also, the obvious clearance can be attributed to the inability to detect the infection [13].

CIN2 and CIN3 are considered H-SIL; however, they evolve in different ways, where CIN2 with lower incidence progresses to cancer, where the percentage of annual regression is 15 to $23 \%$, with regression of up to 55\% in 4-6 years [10], while approximately $2 \%$ of CIN2 lesions develop in CIN3 in the same period. CIN3 is pre-cancer with the potential to progress to invasive cancer at a rate of $0.2 \%$ to $4 \%$ in 12 months [12]. Untreated CIN3 is 30\% likely to become invasive cancer over 30 years, although only about $1 \%$ of properly treated CIN3s become invasive [10].

Most women infected with HPV do not develop CC because the immune response controls the infection, preventing the development of cervical lesions and their progression to cancer [14]. Thus, only a small fraction of infected women cannot control the infection and develop CC. This fact suggests that additional factors may influence the progression of the CIN to CC or its regression.

The link between H-HPV and the development of CC has contributed to the introduction of new screening programmes. Testing for the presence of $\mathrm{H}-\mathrm{HPV}$ is recommended as a screening tool by the WHO and the European Guidelines to ensure the quality of screening for CC [15, 16]. The HPV test is effective in detecting pre-cancerous cervical lesions, particularly in population-based cervical screening programmes [10].

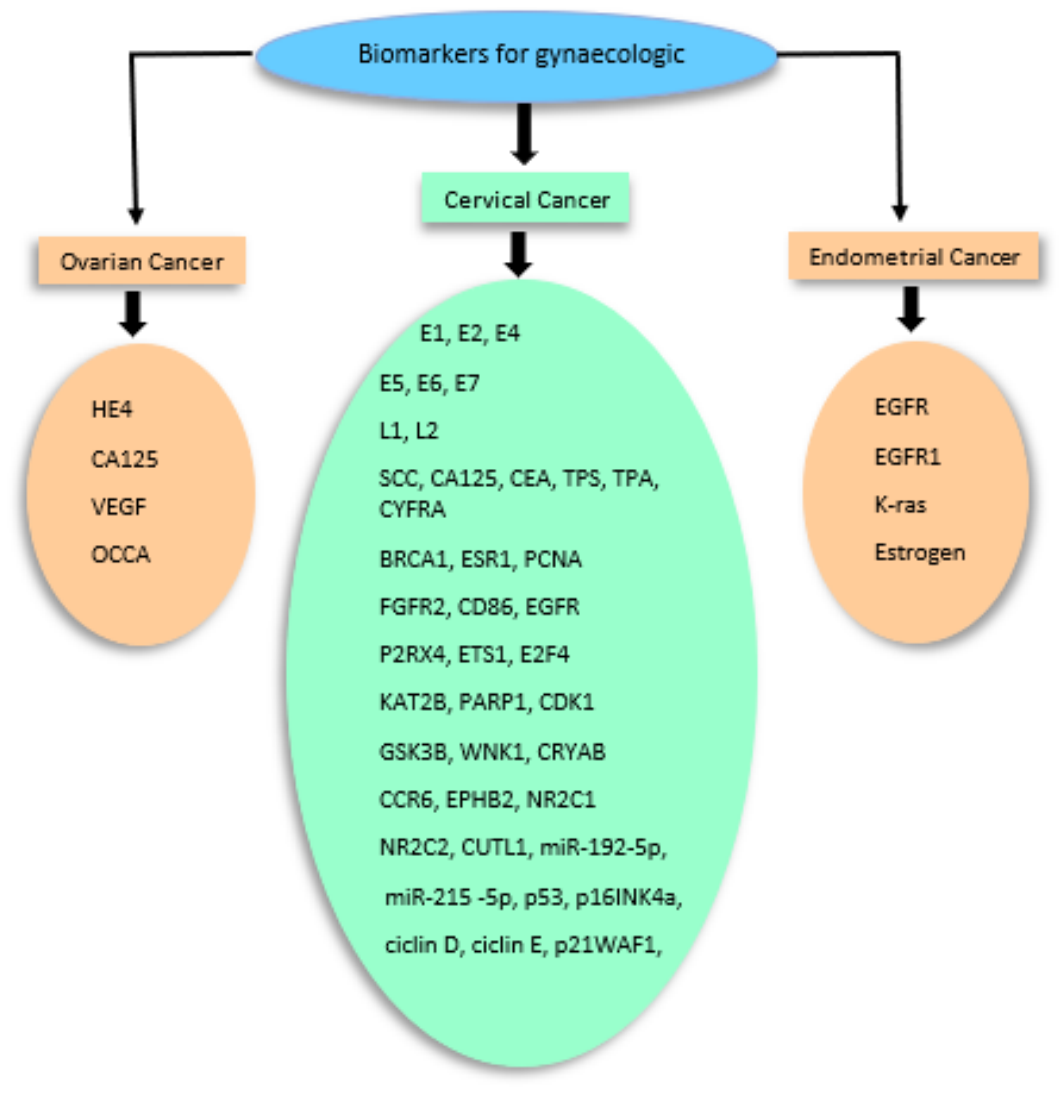

Figure 2 Biomarkers for gynaecologic cancers

Determining the risk and development prognosis, as well as the success of treatment in response to a medication and /or procedure is the main reason for identifying biomarkers. Tumour biomarkers are indicators of the physiological status of changes that occur during the neoplastic process. The expression of these markers may reflect several processes in progress in tumour cells, 
such as hyperproliferation, alteration of gene expression patterns, hyperplasia, genotoxicity, inflammation and enzymatic changes related to the development of the tumour, among others. An ideal tumour biomarker is related to the malignant process, correlates with the tumour mass and allows the characterisation of the tumour type, location, tumour staging, in addition to providing a prognostic assessment of the tumour tissue [10]. There are many biomarkers for CC when compared to other gynaecological cancers, as shown in Figure 2

\subsection{Existing tests for the examination of cervical lesion Pap smear (oncological cytology)}

The Papanicolaou exam (Pap) is still the main method used to detect CC and its precursor lesions [17] and is a cytological screening test that detects abnormal epithelial cells scraped from the transformation zone of the cervix [18]. Several criteria exist to assess the degree of change, including the nucleus/cytoplasm ratio, nuclear shape and intensity of the nuclear marks and chromatin. Currently, the Bethesda classification is the most widely used for cytological diagnosis of cervical samples and categorises abnormal cells in L-SIL and H-SIL [19]. The vast majority of L-SIL represents morphological changes associated with active HPV replication (for example, koilocytosis), while H-SIL indicates cell transformation, characterised mainly by nuclear changes. Epidemiological studies have shown a great impact on the incidence of CC and its precursor lesions when this methodology was used [20]. The p16 / Ki-67 tests cannot recommend screening women with ASCUS or L-SIL cytology due to insufficient high-quality evidence [21].

Despite its great specificity, this methodology has limited sensitivity in detecting precursor lesions of the cervix, a fact that can be attributed to the variation in the interpretation of this method has a variability of 34 to $94 \%$ in the detection of H-SIL and is not decisive in the classification of atypical samples defined as "squamous cells atypical meaning of uncertainty" [19, 22].

\section{Biomarkers}

A biomarker is a characteristic that can be measured as an indicator of normal pathogenic processes or a pharmacological response to a therapeutic intervention. Its main objective is not only to update therapies but also to improve methods to deter the risk assessment of an individual in the development of cancer. Biomarkers are generally found in blood or tissues or even other body fluids, providing a signal for normal or abnormal processes. They can be measured by genetic, proteomic, cellular, or molecular substances found in greater than normal amounts in body fluids (blood, urine) of a cancer patient. An ideal biomarker test would have $100 \%$ sensitivity and specificity, but none of the currently available biomarkers achieves this [22]. The importance of specific biomarkers for CC is demonstrated in some studies in Table 1

\begin{tabular}{|c|c|c|c|c|}
\hline $\begin{array}{c}\text { Authors, study } \\
\text { design, nationality, } \\
\text { and year }\end{array}$ & HPV status & Occupation & Screening method & Conclusion \\
\hline $\begin{array}{l}\text { Gu et al. } \\
2019^{69}\end{array}$ & Positive & $\begin{array}{l}\text { Evaluate HPV } \\
\text { cDNA applications }\end{array}$ & & $\begin{array}{l}\text { Detection of HPV } \\
\text { cDNA in patients } \\
\text { with cervical cancer } \\
\text { could be used as a } \\
\text { dynamic } \\
\text { non-invasive } \\
\text { tumour biomarker, } \\
\text { with high } \\
\text { specificity and } \\
\text { moderate } \\
\text { sensitivity. }\end{array}$ \\
\hline How et al. & Positive & $\begin{array}{l}\text { Identify the CIN70 } \\
\text { gene signature }\end{array}$ & $\begin{array}{l}\text { Total RNA was } \\
\text { extracted from each }\end{array}$ & $\begin{array}{l}\text { Chromosomal } \\
\text { instability plays an }\end{array}$ \\
\hline
\end{tabular}




\begin{tabular}{|c|c|c|c|c|}
\hline $\begin{array}{l}2015 \\
\mathrm{UK}^{38}\end{array}$ & & & $\begin{array}{l}\text { patient sample and } \\
\text { analysed using the } \\
\text { GeneChip Human } \\
\text { Genome U133 Plus } \\
2.0 \quad \text { matrix } \\
\text { (Affymetrix). }\end{array}$ & $\begin{array}{l}\text { important role in } \\
\text { cervical cancer and } \\
\text { is significantly } \\
\text { associated with the } \\
\text { patient's outcome. }\end{array}$ \\
\hline $\begin{array}{l}\text { Nakamura et al. } \\
2019 \\
\text { Japan }^{52}\end{array}$ & & $\begin{array}{l}\text { Association and the } \\
\text { importance of P53 } \\
\text { in gynaecological } \\
\text { cancer }\end{array}$ & & \\
\hline $\begin{array}{l}\text { Zhu et al. } \\
2020^{75}\end{array}$ & Positive & $\begin{array}{ll}\text { Identify the } \\
\text { presence of CC } \\
\text { through DNA }\end{array}$ & $\begin{array}{l}\text { Presence of DNA } \\
\text { methylation and } \\
\text { hydromethylation } \\
\text { in CC }\end{array}$ & \\
\hline $\begin{array}{l}\text { Kelly et al. } \\
2019^{76}\end{array}$ & Positive & $\begin{array}{l}\text { Identify the } \\
\text { presence of CC }\end{array}$ & $\begin{array}{l}\text { Perform a } \\
\text { meta-analysis of } \\
\text { DNA methylation } \\
\text { performance in } \\
\text { women with } \\
\text { high-grade cervical } \\
\text { intraepithelial } \\
\text { neoplasia }(\mathrm{CIN} 2+)\end{array}$ & $\begin{array}{lr}\text { DNA methylation } \\
\text { is significantly } \\
\text { higher in CIN2 + } \\
\text { and CIN3 }+ \\
\text { compared } \\
\text { SCIN1. As a } \\
\text { screening test, } \\
\text { DNA methylation } \\
\text { has greater } \\
\text { specificity than } \\
\text { ASCUS }+ \text { cytology } \\
\text { and greater } \\
\text { sensitivity than } \\
\text { HPV16 / } 18 \\
\text { genotyping. }\end{array}$ \\
\hline $\begin{array}{l}\text { Tornesello et al. } \\
2020^{77}\end{array}$ & Positive & $\begin{array}{l}\text { Interaction between } \\
\text { miRNAs, ln cRNAs } \\
\text { and circRNAs and } \\
\text { their role in cervical } \\
\text { neoplasia. human } \\
\text { genes encoded by } \\
\text { circular RNAs }\end{array}$ & & $\begin{array}{l}\text { The virus-encoded } \\
\text { circE7 } \\
\text { demonstrated } \\
\text { overexpression of } \\
\text { the E7 oncoprotein, } \\
\text { thus contributing to } \\
\text { cell transformation. }\end{array}$ \\
\hline $\begin{array}{l}\text { Ma et al. } \\
2019^{19}\end{array}$ & Positive & $\begin{array}{l}\text { Identify biomarkers } \\
\text { for gynaecological } \\
\text { cancer and the } \\
\text { relevant diagnostic } \\
\text { systems generated } \\
\text { using specific } \\
\text { aptamers. }\end{array}$ & & \\
\hline $\begin{array}{l}\text { Canfell } \\
2019^{14}\end{array}$ & & $\begin{array}{l}\text { Techniques for } \\
\text { eradicating CC }\end{array}$ & $\begin{array}{lr}\text { HPV } & \text { vaccination } \\
\text { and } & \text { cervical } \\
\text { screening } & \text { and } \\
\text { pre-cancer } & \\
\end{array}$ & \\
\hline $\begin{array}{l}\text { Bergman et al. } \\
2019^{78}\end{array}$ & & $\begin{array}{l}\text { To evaluate the } \\
\text { efficacy, } \\
\text { immunogenicity } \\
\text { and damage of }\end{array}$ & $\begin{array}{l}20 \quad \text { randomised } \\
\text { clinical trials with } \\
31,940 \text { participants }\end{array}$ & $\begin{array}{l}\text { A } \\
\text { schedule of HPV } \\
\text { vaccines in young } \\
\text { women results in }\end{array}$ \\
\hline
\end{tabular}




\begin{tabular}{|c|c|c|c|c|}
\hline & & $\begin{array}{l}\text { different dose } \\
\text { schedules and } \\
\text { different types of } \\
\text { HPV vaccines in } \\
\text { women and men }\end{array}$ & & $\begin{array}{l}\text { immune system } \\
\text { responses } \\
\text { comparable to a } \\
\text { three-dose } \\
\text { schedule. }\end{array}$ \\
\hline $\begin{array}{l}\text { Bowden et al. } \\
2019^{79}\end{array}$ & Positive & $\begin{array}{l}\text { Assess how } \\
\text { methylation levels } \\
\text { change with disease } \\
\text { severity and to } \\
\text { determine } \\
\text { diagnostic test } \\
\text { accuracy (DTA) in } \\
\text { detecting } \\
\text { high-grade cervical } \\
\text { intra-epithelial } \\
\text { neoplasia (CIN). }\end{array}$ & $\begin{array}{l}\text { Systematic review } \\
\text { and meta-analysis. } \\
\text { Random effect } \\
\text { models and a } \\
\text { bivariate mixed } \\
\text { effect binary } \\
\text { regression model } \\
\text { were applied to } \\
\text { determine } \\
\text { combined effect } \\
\text { estimates. }\end{array}$ & 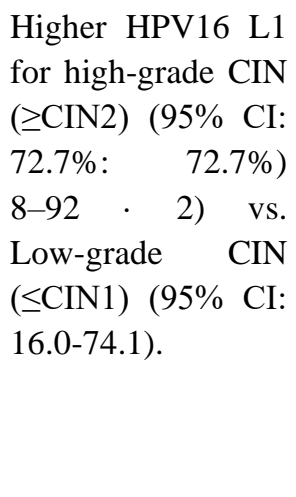 \\
\hline $\begin{array}{l}\text { Gu et al. } \\
2020^{69}\end{array}$ & Positive & $\begin{array}{l}\text { Evaluate } \\
\text { applications } \\
\text { HPV cDNA as a } \\
\text { biomarker in } \\
\text { cervical cancer }\end{array}$ & $\begin{array}{l}684 \text { patients with } \\
\text { WC underwent } \\
\text { meta-analysis }\end{array}$ & \\
\hline $\begin{array}{l}\text { Pal et al. } \\
2019^{9}\end{array}$ & & $\begin{array}{l}\text { Structural, } \\
\text { functional, and } \\
\text { clinical dimensions } \\
\text { of activity E6 and } \\
\text { E7. }\end{array}$ & $\begin{array}{l}\text { The genome } \\
\text { organisation and } \\
\text { protein structure of } \\
\text { E6 and E7 were } \\
\text { discussed, followed } \\
\text { by its mechanism to } \\
\text { establish the six } \\
\text { main characteristics } \\
\text { of cancer in } \\
\text { cervical tissues for } \\
\text { the spread of } \\
\text { tumours. }\end{array}$ & \\
\hline
\end{tabular}

Table 1 shows some recent studies reporting the importance of specific biomarkers for CC.

\subsection{Serum Biomarkers}

Serum biomarkers such as squamous cell antigen carcinoma (SCC-Ag), cancer antigen 125 (CA-125), embryonic carcinoma antigen (CEA) and fragments of cytokeratin (CYFRA) are used to predict prognosis in CC [23].

The advent of high productivity processes that support 'omic' technologies is now contributing to the addition of new biomarkers. Thus, known biomarkers (i.e., BRCA1, ESR1, PCNA, FGFR2, CD86, EGFR, P2RX4, ETS1 and E2F4), as well as new biomolecules (i.e., KAT2B, PARP1, CDK1, GSK3B, WNK1, CRYAB, acid metabolism arachidonic, CCR6, EPHB2, NR2C1, NR2C2, CUTL1, miR-192-5p and miR-215-5p), have been reported using a multi-omics approach on transcription data associated with CC [23]. The proteomics-based analysis shows great promise for the discovery of new and more useful biomarkers.

\subsection{Identification of biomarkers associated with HPV expression oncogenes}

The detection of cellular changes caused by unregulated expression of viral oncoproteins can characterise tumour progression markers and, thus, contribute to the identification of H-SIL cell populations of progression. The identification and establishment of the pattern of alteration of these factors can define markers with high positive predictive power. The use of these markers will 
complement the results of other tests to identify lesions with a higher risk of malignant progression [23].

HPV infections that persist and express viral oncogenes that inactivate p53 and retinoblastoma $(\mathrm{Rb})$ promote increased genomic instability, accumulation of somatic mutations and, in some cases, integration of HPV into the host genome [24]. The association between cancer risk and histological subtypes varies substantially between HPV types, but the reasons for these differences are little known.

The main lines of research associated with these aspects focus mainly on the identification of cellular/tissue or circulating proteins whose expression is altered in response to the expression of viral oncoproteins; investigating changes in the methylation pattern of several cellular genes that could efficiently predict neoplastic initiation; changes in chromosomes and/or viral genome in different regions and recognised as modified by the viral integration event; the identification of polymorphisms associated with a better prognosis [18, 23].

The integration of HPV into the host genome is a critical step in cervical carcinogenesis and is found in almost all invasive CCs and often interrupts the expression of the HPV E2 gene (regulatory protein E2), leading to increases in viral oncoproteins E6 and E7, which in turn promote immortalisation and cellular transformation. Overexpression of the E6 and E7 gene (E7 transforming protein) contributes to marked genomic instability, the accumulation of secondary mutations and malignant transformation [25, 26]. Also, the virus integrates with host genes and regulatory elements, which can cause structural changes in the host's genome and transcriptional deregulation of gene expression [27]. Integration sites often occur in fragile sites common in the genome, but these sites may be less random than originally estimated. Further evaluation of HPV integration sites by the various types of HPV could shed light on other cancer-causing genes [26].

The $8 \mathrm{~kb}$ HPV genomes have CpGs spread across their genes. As the disease progresses, these CpGs are increasingly methylated by the host cell's DNA methyltransferases. This methylation can alter the expression patterns of viral genes that are relevant to the transformation. The DNA hypermethylation of the HPV genome is greater in invasive CC than in cervical dysplasias. Snellenberg et al. (2012) [28] showed that the methylation of several HPV-16, E2 binding sites is significantly higher in invasive CC than in cervical lesions in situ [26, 28].

Studies with immunosuppressed women indicate that a defective immune response is an important factor in the progression of CC. The innate immune system detects damage, activates the secretion of interferons and promotes the secretion of cytokines, which activates Langerhans cells that have antigens in the cervix. The signals of the innate immune system will promote the activation of the adaptive immune system, which generates specific helper T cells $1 \mathrm{CD} 4+$, which, in turn, support the development of effector and cytotoxic CD8 + T cells of memory. HPV-induced diseases are associated with a lack of adequate $\mathrm{HPV}$-specific $\mathrm{CD} 4+$ and $\mathrm{CD} 8+\mathrm{T}$ cell response, leading to immunological tolerance rather than clearance. The proportion of tumour infiltrating CD8 $+\mathrm{T}$ cells in Foxp3 + regulatory $\mathrm{T}$ cells (Treg) appears to be a significant independent prognostic factor in CC [29]. Together, low rates of CD8 + / Treg cells and decreased HLA gene expression is associated with reduced survival in invasive CC [29].

Hereditary susceptibility to invasive CC is also of great clinical interest. The pattern of decreased relative family risk with a decreased degree of genetic relationship indicates that there is a strong relationship between genetics and family aggregation [25]. Variants inherited from the germline have been identified in several important genes in virus-host interactions and immune function $[25,30,31]$. The genes under long-term investigation include HLA class I genes, HLA class II genes and TP53 (tumour protein p53) [25]. Wang et al. (2010) [31] using single nucleotide polymorphism analysis, identified IFNG (interferon, gamma), TMC6 genes (similar to transmembrane channel 6; formerly known as EVER1) and TMC8 (similar to transmembrane channel 8; formerly known as EVER2) associated with progression to CC [31].

Several studies have shown that abnormal promoter hypermethylation leads to silencing or decreased expression of tumour suppressor genes in the CC [32]. These epigenetic changes are believed to be reversible and occur at the beginning of cervical carcinogenesis. The most promising candidate genes are associated with functions such as cell cycle control, apoptosis, cell signalling and 
DNA repair. These candidate genes include DAPK (death-associated protein kinase 1), CDH1 [cadherin 1, type 1, E-cadherin (epithelial)], RASSF1 [member of the Ras 1 association domain (RalGDS / AF-6)], CDKN2A ( cyclin-dependent kinase inhibitor 2A), FHIT (fragile histidine triad), MGMT (O-6-methylguanine-DNA methyltransferase) and RARB (retinoic acid receptor, beta). The cancer cell genome shows global hypomethylation, in addition to hypermethylation of the regional promoter. It has been shown that progressive hypomethylation occurs with increased progression from dysplasia to invasive CC [32]. Hypomethylation, which is believed to contribute to chromosomal instability, can play an important role in the development of invasive diseases. Table 2 shows each biomarker and its expression in the CC.

\begin{tabular}{|c|c|c|}
\hline Biomarkers & $\begin{array}{c}\text { Increased } \\
\text { expression in the } \\
\text { CC }\end{array}$ & $\begin{array}{c}\text { Decreased } \\
\text { expression in the } \\
\text { CC }\end{array}$ \\
\hline 5-caC & $\checkmark$ & \\
\hline $5-f o C$ & $\checkmark$ & \\
\hline 5-hmC & $\checkmark$ & \\
\hline 5-mC & $\checkmark$ & \\
\hline APC & & $V$ \\
\hline BAX & $\checkmark$ & \\
\hline b-catenin & & $\checkmark$ \\
\hline BRAC1 & $\checkmark$ & \\
\hline C4.8 & $\checkmark$ & \\
\hline CA-125 & $\checkmark$ & \\
\hline CAV-1 & $\checkmark$ & \\
\hline $\mathrm{CCNa}$ & & $V$ \\
\hline CCR6 & $\checkmark$ & \\
\hline CD4 & & $V$ \\
\hline $\mathrm{CD} 8$ & & $\checkmark$ \\
\hline CD86 & $\checkmark$ & \\
\hline $\mathrm{CDH} 1$ & & $V$ \\
\hline CDK1 & $\checkmark$ & \\
\hline CDKN2A & & $V$ \\
\hline CEA & $\checkmark$ & \\
\hline CpGs & $\checkmark$ & \\
\hline CRYAB & $\checkmark$ & \\
\hline CUTL1 & $\checkmark$ & \\
\hline cyclin D & $V$ & \\
\hline cyclin E & $V$ & \\
\hline CYFRA & $\checkmark$ & \\
\hline DAPK & & $\checkmark$ \\
\hline DAPK1 & & $\checkmark$ \\
\hline DcR1 & $\checkmark$ & \\
\hline
\end{tabular}




\begin{tabular}{|c|c|c|}
\hline DcR2 & $\checkmark$ & \\
\hline DNMT1 & $\checkmark$ & \\
\hline E1 & $\checkmark$ & \\
\hline E2 & $\checkmark$ & \\
\hline E2F4 & $\checkmark$ & \\
\hline E4 & $\checkmark$ & \\
\hline E5 & $\checkmark$ & \\
\hline E6 & $\checkmark$ & \\
\hline E7 & $\checkmark$ & \\
\hline E-cadherin & & $V$ \\
\hline EGFR & $\checkmark$ & \\
\hline EPHB2 & $\checkmark$ & \\
\hline ESR1 & $\checkmark$ & \\
\hline ETS1 & $\checkmark$ & \\
\hline FANCF & $V$ & \\
\hline FGFR2 & $\checkmark$ & \\
\hline FHIT & & $\checkmark$ \\
\hline GSK3B & $\checkmark$ & \\
\hline HDACs & $\checkmark$ & \\
\hline HIC1 & $\checkmark$ & \\
\hline HLA & & $\checkmark$ \\
\hline hMLH1 & $\checkmark$ & \\
\hline hTERT & $V$ & \\
\hline IFNG & $\checkmark$ & \\
\hline IGF-2 & $\checkmark$ & \\
\hline KAT2B & $V$ & \\
\hline Ki67 & $\checkmark$ & \\
\hline MCM2-7 & $V$ & \\
\hline MDM2 & & $\checkmark$ \\
\hline MGMT & & $\checkmark$ \\
\hline miR-192-5p & $V$ & \\
\hline miR-215-5p & $\checkmark$ & \\
\hline Notch1 & & $\checkmark$ \\
\hline Noxa & $V$ & \\
\hline NR2C1 & $V$ & \\
\hline NR2C2 & $\checkmark$ & \\
\hline ORFs & $\checkmark$ & \\
\hline p16 & $V$ & \\
\hline p16INK4a & $\checkmark$ & \\
\hline p21WAF1 & $\checkmark$ & \\
\hline
\end{tabular}




\begin{tabular}{|l|l|l|}
\hline P27KIP1 & $\checkmark$ & \\
\hline P2RX4 & $\checkmark$ & \\
\hline P53 & & $\checkmark$ \\
\hline p73 & $\checkmark$ & \\
\hline PARP1 & $\checkmark$ & \\
\hline PCNA & $\checkmark$ & \\
\hline PERP & $\checkmark$ & \\
\hline PTEN & $\checkmark$ & \\
\hline PUMA & $\checkmark$ & \\
\hline RARB & $\checkmark$ & \\
\hline RASSF1 & & \\
\hline RASSF1A & $\checkmark$ & \\
\hline Rb & & \\
\hline S100A9 & $\checkmark$ & \\
\hline SCC-Ag & $\checkmark$ & \\
\hline TIMP & $\checkmark$ & \\
\hline TIMP2 & $\checkmark$ & \\
\hline TIMP3 & $\checkmark$ & \\
\hline TMC6 & $\checkmark$ & \\
\hline TMC8 & $\checkmark$ & \\
\hline topoisomerase 2A & & \\
\hline TSLC1 & $\checkmark$ & \\
\hline Tyk2 & $\checkmark$ & \\
\hline VEGF-C & $\checkmark$ & \\
\hline WIF1 & $\checkmark$ & \\
\hline WNK1 & & \\
\hline
\end{tabular}

Table 2: Expression of Biomarkers in the CC

\subsection{Assessment of protein levels involved in cells cycle control}

HPV infection promotes unregulated replication of the host genome and, thus, several proteins involved in the control of the cell cycle have their levels increased or decreased. Studies aim to analyse the levels of proteins related to this event, such as p53, p16INK4a, MCM2-7, EGFR, cyclin D, cyclin E, p21WAF1, p27KIP1, among others [31].

The largest number of studies found in the literature focuses on the assessment of p16INK4a protein levels in CC samples, both in histological sections and in samples derived from cervical stains. The HPV E6 and E7 proteins are known to promote the degradation of tumour proteins p53 and $\mathrm{Rb}$, respectively. This interference activates a negative feedback process that results in the exacerbated expression of the inhibitor protein of the cyclin-dependent kinase complexes, p16INK4a [5].

Studies describe an increase in the expression of these H-SIL and CC in about $100 \%$ of the analysed samples, in contrast to what is observed in the normal epithelium of the CC, where p16INK4a is practically not detected. Approximately $60 \%$ of L-SIL are strongly positive for p16INK4a (proliferating basal and/or parabasal cells), while the remaining $40 \%$ have no detectable 
levels of this protein, although they are positive for HPV DNA and have morphological characteristics associated with infection (koilocytosis, among others). This observation suggests that only a part of the lesions infected with L-HPV disrupted the expression of viral oncoproteins in basal and parabasal cells, whereas, in negative p16INK4a lesions, the expression of these oncoproteins would be very low or even null in this type of cells. Thus, L-SIL that did not have high levels of p16INK4a in the cells of the basal and/or suprabasal layer would be less likely to progress to H-SIL or cancer. It is worth mentioning that the H-SIL of p16INK4a is associated with lesions infected by $\mathrm{H}-\mathrm{HPV}$. The same effect is not seen in positive L-HPV lesions [32].

The analysis of this protein in samples originating from CC showed increased expression of p16INK4a in 98\% of samples derived from H-SIL. Thus, in addition to the research of this protein in CC biopsies, its research patches could be an option in the primary screening of cervical lesions whose classification has not been determined by oncotic cytology [33, 34].

\subsection{Chromosomal instability markers host aneuploidy DNA}

CIN results from chromosomal errors during mitosis, leading to structural and numerical chromosomal abnormalities, besides generating genomic heterogeneity, it promotes inflammatory signalling by introducing double-stranded DNA into the cytosol, involving the cGAS-STING antiviral pathway. These multifaceted effects distinguish CIN as a central driver of tumour evolution and as a genomic source of interference between the tumour and its microenvironment during immunological editing and evasion $[35,36]$.

Aneuploidy denotes an abnormal state in the number of chromosomes; there is a change in the number of chromosomes present in the cells, characterising HPV-positive lesions, including precursor lesions and cancer [36]. Some studies indicate that the presence of aneuploidy precedes viral integration into the host genome in advanced dysplastic lesions, implying that viral integration would be a consequence and not the cause of chromosomal instability. CIN refers to errors in chromosomal segregation in progress over consecutive cell divisions [37, 38]. Both aneuploidy and CIN frequently occur in human cancer, in tumours with a high level of abnormality in the number of chromosomal copies and exhibit evidence of sustained chromosomal dysregulation [35].

Although aneuploidy can be readily evaluated using widely available experimental techniques, such as mass DNA sequencing, fluorescent in situ hybridisation (FISH) or conventional karyotype, CIN can only be inferred indirectly using these methods. The experimental evaluation of CIN must identify the continuous rate of poor chromosomal segregation and can be identified through the frequency of cells in anaphase (phase of mitosis characterised by the migration of chromatids towards opposite poles of the cell), clonal assays, sequencing of a single cell with the reconstruction of a phylogenetic tree or sequencing of a multiregional tumour considering the information of the specific copy number of the allele [37, 38, 39, 40].

It is estimated that $60-80 \%$ of human tumours exhibit chromosomal abnormalities suggestive of CIN [41, 42]. CIN correlates positively with the tumour stage and is enriched in recurrent and metastatic tumour specimens [35, 43, 44]. Also, complex aneuploidies and the duplication of polyploidies resulting from the entire genome are characteristic of tumour types with a predilection for metastasis, resistance to treatment and decreased overall survival, such as CC [42, 45, 46].

Oncogenic signalling, pre-mitotic replication stress and defects in centrosome replication, sister chromatid cohesion, signalling of the spindle assembly checkpoint or microtubule connections to chromosomes have been shown to induce CIN. Also, a wide variety of antineoplastic therapies used in the initial treatment or metastatic configurations can disrupt the fidelity of chromosomal segregation during anaphase $[47,48]$.

\subsection{HPV Integration}

Based on DNA sequence data, more than 200 types of HPV have been identified that have genomic differences. Eighty-five HPV genotypes are well-characterised. Another 120 isolates are partially characterised as potential new genotypes [49]. 
HPV DNA is believed to randomly integrate into the host's genome during the repair process that is triggered after ruptures in the double-stranded cell genome begin. Viral integration would be an indicator of genomic instability during the cell transformation process since 80 to $90 \%$ of CC samples have integrated HPV DNA [34].

The HPV genome has a single circular double-stranded DNA molecule containing approximately 7,900 bp associated with histones [50]. All protein-coding sequences in the open reading frame $(\mathrm{ORF})$ are presented on tape. The genome is functionally divided into three regions: (i) The first is a non-coding regulatory region upstream of 400 to $1,000 \mathrm{bp}$, which has been referred to as the non-coding region, the long control region (LCR) or higher regulatory region, which contains the p97 nucleus promoter along with the enhancer and silencing sequences that regulate DNA replication by controlling the transcription of ORFs, in addition to presenting the greatest degree of variation in the viral genome 53 (ii) The second initial region expresses ORFs E1, E2, E4, E5, E6 and E7, which are involved in viral replication and oncogenesis. (iii) The third is a late region, which encodes structural proteins L1 and L2 for the viral capsid.

Several methodologies are described to detect the integration of HPV DNA in the viral genome, such as the real-time polymerase chain reaction (qPCR) technique that allows obtaining a relationship between E2 levels (often interrupted in viral integration) and the HPV E6 / E7 genes. When not integrated, the viral genome would have a 1: 1 ratio between the E2 and E6 / E7 genes and the integration of the viral genome would result in a decrease in the genetic detection of E2 [5].

Currently, the commonly used diagnostic markers include proteins related to HPV L1, E6 and E7. The main protein in capsid viruses is L1, produced in the cytoplasm. E6 and E7 are primary HPV oncoproteins with multiple cell targets, including p53, and the retinoblastoma tumour suppressor protein (pRB). E6 inhibits p53 to prevent apoptosis, while E7 is the primary transforming protein and inhibits pRB to regulate cell cycle stop [51]. Telomeres are specialised structures, located at the ends of chromosomes, known to be essential for the stability of the genome [51, 52]. Telomere dysfunction and telomerase activation have previously been implicated in the progression of human cancer [51, 53]. The expression of hTERT is known to be the rate-limiting factor for human telomerase activity and a more sensitive indicator of telomerase function and activity than the expression levels of other telomerase subunits that are expressed constitutively in normal and cancerous cells [51]. Ki67 is a nuclear antigen expressed during all active phases of the cell cycle (G1, S, G2 and M) and its level of expression can be used to determine the state of proliferation and predict tumour development [51].

Screening for these diagnostic markers can also be useful in assessing the progression of CC after the intermediate stage, as demonstrated by a prospective study previously carried out on its expression in histological, clinical formalin-fixed and paraffin-embedded (FFPE) samples. Cytological samples used in clinical screening tests were also performed [54]. However, samples of severe pre-cancerous lesions were not sufficient to conduct statistical analysis. It usually takes a long time to collect samples of H-SIL, which are the most serious pre-cancerous lesions in cancer.

A significant percentage of L-SIL and H-SIL have copies of HPV in episomal form, in addition to integrated copies. This aspect interferes with the direct quantification of the number of integrated viral copies. Some studies assess the location of HPV integration in the viral genome. This criterion may be valid in women after previous treatment, since the integration site identified may be a tumour marker in a possible recurrence [34].

\subsection{Evaluation of polymorphisms and epigenetic events in the p53 gene}

P53 plays an important role in regulating cell proliferation, DNA repair, apoptosis, genomic stability, senescence and metabolic homeostasis [55]. The p53 protein activated by several signals acts as a transcription factor. When DNA is damaged, p53 induces the expression of cyclin-dependent p2 (kinase inhibitor) (CDK) that suppresses the cyclin-CDK complexes, resulting in the cell cycle stopping in the G1 phase. The G1 arrest may allow DNA repair before S1 replication [34]. If cells cannot repair DNA damage, p53 induces apoptosis by activating apoptosis signal genes, such as BAX, PUMA, Noxa and PERP. The loss of p53 function allows abnormal cell proliferation 
and is strongly associated with carcinogenesis. P53 dysfunction has been observed in many malignant tumours [34].

This dysfunction occurs due to the inactivation of the p53 protein by binding proteins or TP53 mutations. MDM2 plays the role of a negative regulator by direct connection. The MDM2 protein acts as a ubiquitin E3 ligase recognising the $\mathrm{N}$-terminal transactivation domain (TAD) of the tumour suppressor p53 and as an inhibitor of transcriptional p53 activation. In response to DNA damage, MDM2 releases p53, resulting in its activation [56]. In the CC, p53 is inactivated by the HPV E6 oncoprotein [34]. The results on the prognostic impact of p53 overexpression in granulosa cell tumours are conflicting. Mutations in TP53 have been seen in about half of patients with malignant tumours [34, 57].

P53 inactivation is associated with CC carcinogenesis. Notch1 acts as a tumour suppressor gene $[34,58]$ and induces cell differentiation in keratinocytes, [34, 59] by reducing cell proliferation in CC cell lines through oncogenes E6 and E7. Yugata et al. (2007) [60] demonstrated that E6 suppressed the expression of Notch 1 by inactivating p53 and binds directly to the Notch1 promoter, regulating the expression of Notch1 at the transcriptional level. In CC carcinogenesis, the promotion of p53 degradation by E6 reduces Notch1 expression [61].

E6 and E7 can immortalise cervical cells independently and synergistically. INK4A inhibits the function of E6, while E7 suppresses this inhibition. On the other hand, E6 inhibits apoptosis induced by E7 by degrading apoptosis-inducing proteins p53 [62]. In an in vitro experiment, only epithelial cells that express E6 or E7 could not be immortalised, supporting the importance of the synchronic function of E6 and E7 in cervical carcinogenesis [34].

\subsection{Evaluation of epigenetic events}

Additional genetic and epigenetic changes in the host cell genome are necessary for progression to CC. Methylation of cytosines at $\mathrm{CpG}$ sites in promoter regions can lead to gene silencing. DNA methyltransferases (DNMTs) responsible for CpG methylation can be activated by E6 and E7, where E7 can bind directly and activate DNMT1, while E6 can positively regulate DNMT1 through p53. On the other hand, silencing E6 and E7 has been shown to reduce DNA methylation of tumour suppressor genes and restore the phenotype transformed into CC cells. Increased levels of DNA methylation of several tumour suppressor genes (candidates) are associated with CC and a subset of its H-SIL CIN 2 and 3 [63].

Methylation is the main epigenetic phenomenon by which a gene is silenced, being an important means of regulating gene expression [64]. Particularly susceptible to the effect of methylation are CPG dinucleotides, which contain cytosine and guanine bases. Most of these dinucleotides are in small regions, called CpG islands, which are demethylated in normal cells. These regions are generally found in the regulatory sequences present at the 5' end of each gene, where the genetic promoters are located. Methylation of these regions interrupts the transcription of genes by silencing their promoters. This event can also be observed in the histone structure [37].

Epigenetics is a well-studied phenomenon, involved in several biological processes, including development, cell differentiation, immune function and various stages of carcinogenesis [38]. Reference studies using exome sequencing have identified only a small proportion of mutations in classic tumour suppressor genes, such as TP53 and Rb1 in CC, because these proteins are inactivated by oncogenic H-HPV proteins, such as E6 and E7 [5, 38].

The hypermethylation of the specific gene and the role of global DNA hypomethylation has been well-recognised during the progression from premalignant conditions to malignant diseases fully developed in the CC. The analysis of global hypomethylation explains the underlying mechanisms of carcinogenesis that may occur due to crude chromosomal instability and reactivation of transposable elements and, subsequently, oncogenic expression [23, 38].

The acetylation, methylation and phosphorylation of histones play a significant role in the regulation of gene expression in normal cells. Any aberration in histone modifications can facilitate the inadequate transcription and transformation of normal cells, disrupting cell proliferation and cell death [39]. Immunohistochemical analysis of histone $\mathrm{H3}$ phosphorylation and acetylation 
showed a significant association with CC progression [40]. Viral oncoproteins derived from HPV E6 and E7 bind histones acetylases (HDACs) and histones acetyltransferases, which are the main enzymes involved in the modification of histone and the regulation of gene expression [5, 40].

It is known that the synergistic effect of DNA hypermethylation and histone acetylation is necessary for the modulation of expression throughout the genome, as well as at the individual genetic level. miRNA-mediated post-transcriptional regulation of gene expression is an epigenetic event implicated in several human diseases, including cancer. Studies have highlighted the role of miRNAs during the progression of CC based on their expression in clinical samples and their usefulness as a diagnostic marker. Also, DNA methylation and histone modifications, and miRNA regulation of gene expression provide an additional layer of complexity to understand the role of epigenetics during CC progression [36, 38].

Unlike genetic changes, epigenetic changes are reversible, tissue-specific and governed by gene-environment interactions. The specificity, dynamics and reversible nature of epigenetic changes provide an opportunity for preventive, diagnostic, prognostic and therapeutic interventions [23], but there are situations where methylation contributes to pathogenic processes, such as cancer, and hypermethylation of certain regions of DNA can be considered a factor for the formation of tumours, interfering in several ways in the process of carcinogenesis, such as the methylation of tumour-suppressor gene promoting regions, where the main function of the originated proteins is to control the proliferation of cells, and, with that, the loss of this type of regulation is related to neoplastic processes. Hypermethylation of the 5th region of the gene encoding $\mathrm{pRb}$ is an example of silencing a tumour suppressor gene and the oncogenetic process. Senescent cells and/or that have been affected by environmental factors, such as radiation, smoke, exposure to certain viruses, and other aspects, have a higher incidence of hypermethylation in genes associated with the neoplastic process [65].

In CC, methylation of several genes is described and the main examples are DcR1 / DcR2, hTERT, p73, p16, PTEN, E-cadherin, APC, MGMT, FANCF, BRAC1, hMLH1, RASSF1A, DAPK, TSLC1, FHIT, HIC1, RAR $\beta$, TIMP2 / TIMP3, CAV-1. As methylation markers, 5-hmC and 5-mC together with 5-foC and 5-caC draw the reversible cycle outline, and 6-mA participates in RNA methylation, especially miRNA $(\mathrm{Gu}, 2020)$. The silencing of the epigenetic gene through dense methylation of DNA within the CpG islands occurs in the CC associated with HPV. Tumour suppressor genes (TSGs) are common targets for gene silencing in this disease. The identification of a TSG panel has great promise to provide a powerful set of DNA methylation biomarkers for use in the diagnosis and/or prognosis of the disease [66].

The genes that encode several major regulators of the Wnt / $\beta$-catenin oncogenic pathway, such as CDH1 (E-cadherin), APC and WIF1, are often silenced by dense methylation of their promoter regions in CC [66]. Other genes supposedly hypermethylated in CC with little or no methylation in normal or low-grade CINs include DAPK1, RARB, TIMP, CCNa and FHIT [66].

Pyrosequencing bisulfite has recently emerged as a quantitative method for measuring DNA methylation at individual CPG sites within a population of DNA molecules that can be used with a variety of biological specimens, making this approach amenable to use in the clinical environment [66].

\section{Perspectives in the identification of biomarkers for CC}

\subsection{Changes in gene expression}

Studies seek to identify differentially expressed genes using the cDNA microarray technique. Among them, tumorigenic and non-tumorigenic strains are compared to the positive points of HPV16, with the identification of 49 differentially expressed genes, such as the C4.8 gene, whose protein is associated with cell proliferation and its expression is increased in H-SIL [29, 35].

Comparing the gene expression profile between CC and normal keratinocytes understudy, more than 500 differentially expressed genes; among them, biomarkers such as CDKN2A / p16INK4a, topoisomerase 2A, among others [5]. A study identified transcripts of kallikrein 7 and 
superoxide dismutase 2 when compared to strains immortalised with HPV16 and HPV18 for primary cultures of normal keratinocytes [26].

Study of squamous H-SIL intraepithelial lesions in 40 patients caused by HPV16 infection showed lower levels of E-cadherin after HPV16 E6 / E7 gene expression [35]. This decrease led to the promotion of cell proliferation and increased cell migration and invasion due to weaker cell adhesion properties [35]. Also, reduced levels of E-cadherin and b-catenin were observed in $135 \mathrm{CC}$ samples, which were associated with histological differentiation, metastasis and recurrence, suggesting that the state of e-cadherin could serve as a prognostic biomarker.

\subsection{Change of protein expression and markers identified using the mass spectrometry (MS) technique}

Some circulating markers detected by an enzyme immunoassay (ELISA) have been indicated to detect CC, including IGF-2, VEGF-C and CIFRA proteins [43]. Also, methylation of the CDH1 and $\mathrm{CDH} 2$ genes was analysed in serum in samples [31]. Although these standard bioanalytical methods, such as ELISA and electrochemical immunoassay (ECLIA), are still common in medicine for protein evaluation, several studies have focused on technology-based MS.

The first studies for proteomic analysis, called SELDI MS (enhanced surface laser desorption and ionisation mass spectrometry) were to identify circulating protein markers characteristic of situ CC. This technique allows the tracking of hundreds of proteins differentially expressed in body fluids, such as plasma, saliva, urine and others. Some studies have described plasma protein profiles capable of discriminating patients with or without CC, with sensitivity and specificity ranging from 87 to $92 \%$ and 97 to $100 \%$, respectively [31, 43].

Gu et al. (2015) [67] reported proteomic analysis of high-grade dysplastic cervical cells obtained from ThinPrep slides using a linear ion trap along with MS with Fourier transform (LTQ-FT MS). They identified more than 1000 biomarkers of candidate proteins for high-grade dysplastic cervical cells and laser capture microdissection was used to isolate high-grade and normal dysplastic cells. The research indicated that proteomics could improve screening for CC. In another study, two-dimensional gel electrophoresis was used to separate proteins from 10 pairs of squamous human CC tissues and combined samples from the unaffected adjacent cervix [36]. Differentially expressed proteins were identified by matrix-assisted MS (MALDI-ToF MS). Overexpression of Tyk2, S100A9 and zinc finger protein 217 in scaly CC was observed.

Two-dimensional differential gel electrophoresis (2D-DIGE) accompanied by MALDI-ToF MS was performed by Guo et al. (2015) [68] in quantitative analysis of plasma proteins of women with early-stage CC. Ten plasma proteins that could be used as biomarkers were identified, such as proteins related to lipid metabolism: apolipoprotein A-IV (APOA4), apolipoprotein A1 (APOA1), apolipoprotein E (APOE); metabolic enzymes: ceruloplasmin (CP), endoglycosidase F2, mannan-binding lectin serine protease 2 (MASP2), glycoprotein CLU and proteins related to immune function. The same method was used by Guo et al. (2015) [68] to research predictive markers of response to neoadjuvant chemotherapy in patients with CC. The proteins were evaluated in 10 cases of the advanced CC of patients who received cisplatin-based neoadjuvant chemotherapy. The study showed that overexpression of Hsp70 inhibited the effectiveness of cisplatin and, therefore, Hsp70 was evaluated as a potential biomarker of sensitivity to chemotherapy [68].

Yin et al. (2016) [69] identified two metabolites, phosphatidylcholine and lymphosoftidylcholine, which are significantly reduced and overloaded in CC plasma compared to patients with uterine fibroids, using MS by ultra-performance liquid chromatography (UPLC-MS). The authors suggest that these lipids may serve as new biomarkers to facilitate the diagnosis of CC. sing gas chromatography-mass spectrometry (GC-MS), Godoy-Vitorino et al. (2018) [70] identified three urinary metabolites, 5-oxoprolinate, erythronic acid and $\mathrm{N}$-acetylaspartic acid, which discriminate positive HPV with simultaneous H-SIL of controls negative. These metabolites are known to be involved in a variety of biochemical processes related to energy and metabolism and are likely to be biomarkers for H-HPV infection. 
Recently, Longuespée et al. (2019) [71] used data from a biomarker discovery study to correlate $\mathrm{m} / \mathrm{z}$ of MALDI images with masses of peptides identified by LC-MS / MS in the high-grade squamous intraepithelial lesion. This concept combines LC-MS / MS-based on quantitative proteomics with MALDI images and allows for the reliable identification of peptides. The authors assigned identifications to three $\mathrm{m} / \mathrm{z}$ of interest. This may represent an interesting option for further confirmation of the peptide identity.

Further analysis of protein expression is needed, as new biomarkers designed using MS-based proteomics tools can greatly improve the diagnosis and treatment of CC.

\section{Conclusion}

Currently, several biomarkers associated with CC are being analysed. The most convincing data are associated with the persistent detection of the H-HPV genome, as well as the study of p16INK4a expression through immunohistochemistry regarding the evaluation of HPV transcripts E6 / E7 type 16, 18, 31, 33 and 45 in CC samples has become quite popular. Serum biomarkers are used to predict the prognosis; the detection of cellular changes due to unregulated expression of viral oncoproteins can characterise tumour progression markers, as well as the silencing of the expression of tumour suppressor genes. It is estimated that $60-80 \%$ of human tumours exhibit chromosomal abnormalities and, with the use of the cDNA microarray technique, the identification of differentially expressed genes can happen, as well as the pyrosequencing bisulfite that has emerged as a quantitative method for measuring methylation of DNA within a population of DNA molecules. The sum of several biomarker identification techniques, as well as the understanding of the mechanism of action of each one of them and their importance in the development of the disease, is the solution found to overcoming deaths from CC in developing countries.

\section{Abbreviation}

\begin{tabular}{ll} 
APOA1 & Apolipoprotein A1 \\
APOA4 & Apolipoprotein A-IV \\
APOE & Apolipoprotein E \\
CA-125 & Cancer antigen 125 \\
CC & Cervical Cancer \\
CDK & Cyclin-dependent kinase \\
CEA & Carcinoma antigen \\
CIN & Cervical intraepithelial neoplasia \\
CP & Ceruloplasmin \\
CYFRA & Cytokeratin fragments \\
DAPK & Death-associated protein kinase 1 \\
DES & Diethylstilbestrol \\
DNA & Deoxyribonucleic acid \\
DNMTs & DNA methyltransferases \\
ECLIA & Electrochemical immunoassay \\
ELISA & Enzyme-linked immunosorbent assay (ELISA \\
FFPE & Formalin and embedded in paraffin \\
FHIT & Fragile histidine triad \\
GC-MS & Chromatography-mass spectrometry \\
HDACs & Histone acetylases \\
HPV & Human Papillomavirus \\
H-SIL & High-grade squamous intraepithelial lesion \\
IFNG & Interferon, gamma \\
LCR & Long control region \\
L-SIL & Low-grade squamous intraepithelial lesion \\
LTQ-FT MS & Linear ion trap along with a Fourier transform mass spectrometer \\
MALDI-ToF MS & Matrix-assisted mass spectrometry \\
\hline &
\end{tabular}




$\begin{array}{ll}\text { MASP2 } & \text { Mannan-binding lectin serine protease 2 } \\ \text { miRNAs } & \text { microRNA } \\ \text { ORF } & \text { Open reading frame } \\ \text { Pap } & \text { Pap smear } \\ \text { pRb } & \text { Protein retinoblastoma } \\ \text { qPCR } & \text { Real-time polymerase chain reaction } \\ \text { RARB } & \text { Retinoic acid receptor beta } \\ \text { Rb } & \text { Retinoblastoma } \\ \text { SCC-Ag } & \text { Squamous cell carcinoma antigen } \\ \text { SELDI MS } & \text { Enhanced surface laser desorption and ionisation mass spectrometry } \\ \text { TAD } & \text { Transactivation domain } \\ \text { TSGs } & \text { Tumour suppressor genes } \\ \text { TP53 } & \text { Tumour protein p53 } \\ \text { UPLC-MS } & \text { Ultra-performance liquid chromatographic-mass spectrometry } \\ \text { WHO } & \text { World Health Organization } \\ \text { 2D-DIGE } & \text { Two-dimensional differential gel electrophoresis }\end{array}$

\section{Funding}

MU is funded by the AC Camargo Cancer Center. MS is funded by the EPSRC and the Imperial College London [EP/N509486/1: 1979819].

\section{Competing interests}

The authors declare that they have no competing interests.

\section{References}

1. Bray, F.; Ferlay, J.; Soerjomataram, I.; Siegel, R.L.; Torre, L.A.; Jemal, A. Global cancer statistics 2018: GLOBOCAN estimates of incidence and mortality worldwide for 36 cancers in 185 countries. CA Cancer J Clin. 2018, 68, 394-424, doi: 10.3322/caac.21492.

2. Torre, L.A.; Islami, F.; Siegel, R.L.; Ward, E.M.; Jemal, A. Global Cancer in Women: Burden and Trends. Cancer Epidemiol Biomarkers. 2017, 26, 444-457, doi: 10.1158/1055-9965.EPI-16-0858.

3. LaVigne, A.W.; Triedman, S.A.; Randall, T.C.; Trimble, E.L.; Viswanathan, A.N. Cervical cancer in lowand middle-income countries: Addressing barriers to radiotherapy delivery. Gynecol Oncol Rep. 2017, 1, 16-20, doi: 10.1016/j.gore.2017.08.004.

4. American Cancer Society (2018). Cancer facts and figures 2018. Atlanta, GA: American Cancer Society; Available online: https://www.cancer.org/cancer/cervical-cancer/causes-risks-prevention/risk-factors.html (accessed on June 15, 2020).

5.

6. Pal, A.; Kundu, R. Human Papillomavirus E6 and E7: The Cervical Cancer Hallmarks and Targets for Therapy. Front Microbiol. 2020, 21, 3116, doi: 10.3389/fmicb.2019.03116.

7. Egawa, N.; Doorbar, J. The low-risk papillomaviruses. Virus Res. 2017, 2, 119-127. doi: 10.1016/j.virusres.2016.12.017.

8. de Villiers, E.M.; Fauquet, C.; Broker, T.R.; Bernard, H.U.; zur Hausen, H. Classification of papillomaviruses. Virology. 2004, 20, 17-27. doi: 10.1016/j.virol.2004.03.033.

9. Clifford, G.M.; Smith, J.S.; Aguado, T.; Franceschi, S. Comparison of HPV type distribution in high-grade cervical lesions and cervical cancer: a meta-analysis. Br J Cancer. 2003, 7, 101-5. doi: 10.1038/sj.bjc.6601024.

10. Braaten, K.P.; Laufer, M.R. Human Papillomavirus (HPV), HPV-Related Disease, and the HPV Vaccine. Rev Obstet Gynecol. 2008, 1, 2-10.

11. Chan, C.K.; Aimagambetova, G.; Ukybassova, T.; Kongrtay, K.; Azizan, A. Human Papillomavirus Infection and Cervical Cancer: Epidemiology, Screening, and Vaccination-Review of Current Perspectives. J Oncol. 2019, 10, 3257939. doi: 10.1155/2019/3257939.

12. Insinga, R.P.; Dasbach, E.J.; Elbasha, E.H. Epidemiologic natural history and clinical management of Human Papillomavirus (HPV) Disease: a critical and systematic review of the literature in the 
development of an HPV dynamic transmission model. BMC Infect Dis. 2009, 29, 119, doi: 10.1186/1471-2334-9-119.

13. Moscicki, A.B.; Ma, Y.; Wibbelsman, C.; Darragh, T.M.; Powers, A.; Farhat, S.; Shiboski, S. Rate of and risks for regression of cervical intraepithelial neoplasia 2 in adolescents and young women. Obstet Gynecol. 2010, 116, 1373-80, doi: 10.1097/AOG.0b013e3181fe777f.

14. Skinner, S.R.; Wheeler, C.M.; Romanowski, B.; Castellsagué, X.; Lazcano-Ponce, E.; Del Rosario-Raymundo, M.R.; Vallejos, C.; Minkina, G.; Pereira Da Silva, D.; McNeil, S.; et al. VIVIANE Study Group. Progression of HPV infection to detectable cervical lesions or clearance in adult women: Analysis of the control arm of the VIVIANE study. Int J Cancer. 2016, 15, 2428-38, doi: 10.1002/ijc.29971.

15. Shulzhenko, N.; Lyng, H.; Sanson, G.F.; Morgun, A. Ménage à trois: an evolutionary interplay between human papillomavirus, a tumor, and a woman. Trends Microbiol. 2014, 22, 345-53, doi: 10.1016/j.tim.2014.02.009.

16. WHO. Comprehensive control of cervical cancer: a guide to essential practice. 2nd. Geneva, Switzerland: WHO; $2014 . \quad$ Avaiable online: https://www.who.int/reproductivehealth/publications/cancers/cervical-cancer-guide/en/ (accessed on: June, 24, 2020).

17. Arbyn, M.; Anttila, A.; Jordan, J.; Ronco, G.; Schenck, U.; Segnan, N.; Wiener, H.; Herbert, A.; von Karsa, L. European Guidelines for Quality Assurance in Cervical Cancer Screening. Second edition--summary document. Ann Oncol. 2010, 21, 448-458, doi: 10.1093/annonc/mdp471.

18. Ma, X.; Lakshmipriya, T.; Gopinath, S.C.B. Recent Advances in Identifying Biomarkers and High-Affinity Aptamers for Gynecologic Cancers Diagnosis and Therapy. J Anal Methods Chem. 2019, 8, 5426974, doi: $10.1155 / 2019 / 5426974$.

19. Winer, R.L.; Lin, J.; Tiro, J.A.; Miglioretti, D.L.; Beatty, T.; Gao, H.; Kimbel, K.; Thayer, C.; Buist, D.S.M. Effect of Mailed Human Papillomavirus Test Kits vs Usual Care Reminders on Cervical Cancer Screening Uptake, Precancer Detection, and Treatment: A Randomized Clinical Trial. JAMA Netw Open. 2019, 1, 1914729, doi: 10.1001/jamanetworkopen.2019.14729.

20. Ronco, G.; Dillner, J.; Elfström, K.M.; Tunesi, S.; Snijders, P.J.; Arbyn, M.; Kitchener, H.; Segnan, N.; Gilham, C.; Giorgi-Rossi, P.; et al. International HPV screening working group. Efficacy of HPV-based screening for prevention of invasive cervical cancer: follow-up of four European randomised controlled trials. Lancet. 2014, 8, 524-32, doi: 10.1016/S0140-6736(13)62218-7.

21. IARC - International Agency for Research on Cancer-World Health Organization. IARC monographs on the assessment of cancer risks to humans: human papillomaviruses. 2007. Vol. Available online: URL: https://www-dep.iarc.fr/ (accessed on: June, 25, 2020).

22. Lopes, V.A.S.; Ribeiro, J.M. Cervical cancer control limiting factors and facilitators: a literature review. Cien Saude Colet. 2019, 9, 3431-3442, doi: 10.1590/1413-81232018249.32592017.

23. Dasari, S.; Wudayagiri, R.; Valluru, L. Cervical cancer: Biomarkers for diagnosis and treatment. Clin Chim Acta. 2015, 20, 7-11, doi: 10.1016/j.cca.2015.03.005.

24. Won, S.; Kim, M.K.; Seong, S.J. Clinical management of abnormal Pap tests: differences between US and Korean guidelines. J Pathol Transl Med. 2020, 54, 213-219, doi: 10.4132/jptm.2020.03.11.

25. Moody, C.A.; Laimins, L.A. Human papillomavirus oncoproteins: pathways to transformation. Nat Rev Cancer. 2010, 10, 550-60, doi: 10.1038/nrc2886.

26. Rader J. Host and viral genetics and risk of cervical cancer. In: Welsch P; ed. The role of genetics in breast and reproductive cancers. New York, Springer; 2009, 263-84.

27. Uyar, D.; Rader, J. Genomics of cervical cancer and the role of human papillomavirus pathobiology. Clin Chem. 2014, 60, 144-6, doi: 10.1373/clinchem.2013.212985.

28. Schmitz, M.; Driesch, C.; Beer-Grondke, K.; Jansen, L.; Runnebaum, I.B.; Dürst, M. Loss of gene function as a consequence of human papillomavirus DNA integration. Int J Cancer. 2012, 1, E593-602, doi: 10.1002/ijc.27433.

29. Snellenberg, S.; Schütze, D.M.; Claassen-Kramer, D.; Meijer, C.J.; Snijders, P.J.; Steenbergen, R.D. Methylation status of the E2 binding sites of HPV16 in cervical lesions determined with the Luminex® xMAP ${ }^{\text {TM }}$ system. Virology. 2012, 20, 357-65, doi: 10.1016/j.virol.2011.11.006.

30. Jordanova, E.S.; Gorter, A.; Ayachi, O.; Prins, F.; Durrant, L.G.; Kenter, G.G.; van der Burg, S.H.; Fleuren, G.J. Human leukocyte antigen class I, MHC class I chain-related molecule A, and CD8+/regulatory T-cell ratio: which variable determines survival of cervical cancer patients? Clin Cancer Res. 2008, 1, 2028-35. doi: 10.1158/1078-0432.CCR-07-4554. 
31. Chen, D.; Juko-Pecirep, I.; Hammer, J.; Ivansson, E.; Enroth, S.; Gustavsson, I.; Feuk, L.; Magnusson, P.K.; McKay, J.D.; Wilander, E.; et al. Genome-wide association study of susceptibility loci for cervical cancer. J Natl Cancer Inst. 2013, 1, 624-33. doi: 10.1093/jnci/djt051.

32. Wang, S.S.; Gonzalez, P.; Yu, K.; Porras, C.; Li, Q.; Safaeian, M.; Rodriguez, A.C.; Sherman, M.E.; Bratti, C.; Schiffman, M.; et al. Common genetic variants and risk for HPV persistence and progression to cervical cancer. PLoS One. 2010, 13, e8667, doi: 10.1371/journal.pone.0008667.

33. Lu, Q.; Ma, D.; Zhao, S. DNA methylation changes in cervical cancers. Methods Mol Biol. 2012, 863, 155-76, doi: 10.1007/978-1-61779-612-8_9.

34. Snoek, B.C.; Babion, I.; Koppers-Lalic, D.; Pegtel, D.M.; Steenbergen, R.D. Altered microRNA processing proteins in HPV-induced cancers. Curr Opin Virol. 2019, 39, 23-32, doi: 10.1016/j.coviro.2019.07.002.

35. Nakamura, M.; Obata, T.; Daikoku, T.; Fujiwara, H. The Association and Significance of p53 in Gynecologic Cancers: The Potential of Targeted Therapy. Int J Mol Sci. 2019, 4, 5482. doi: 10.3390/ijms20215482.

36. Bakhoum, S.F.; Cantley, L.C. The Multifaceted Role of Chromosomal Instability in Cancer and Its Microenvironment. Cell. 2018, 6, 1347-1360, doi: 10.1016/j.cell.2018.08.027.

37. How, C.; Bruce, J.; So, J.; Pintilie, M.; Haibe-Kains, B.; Hui, A.; Clarke, B.A.; Hedley, D.W.; Hill, R.P.; Milosevic, M.; et al. Chromosomal instability as a prognostic marker in cervical cancer. BMC Cancer. 2015, 6, 15:361, doi: 10.1186/s12885-015-1372-0.

38. Bakhoum, S.F.; Danilova, O.V.; Kaur, P.; Levy, N.B.; Compton, D.A. Chromosomal instability substantiates poor prognosis in patients with diffuse large B-cell lymphoma. Clin Cancer Res. 2011, 15, 7704-11, doi: 10.1158/1078-0432.CCR-11-2049.

39. Bakker, B.; Taudt, A.; Belderbos, M.E.; Porubsky, D.; Spierings, D.C.; de Jong, T.V.; Halsema, N.; Kazemier, H.G.; Hoekstra-Wakker, K.; Bradley, A.; et al. Single-cell sequencing reveals karyotype heterogeneity in murine and human malignancies. Genome Biol. 2016, 31, 115, doi: 10.1186/s13059-016-0971-7.

40. Jamal-Hanjani, M.; Wilson, G.A.; McGranahan, N.; Birkbak, N.J.; Watkins, T.B.K.; Veeriah, S.; Shafi, S.; Johnson, D.H.; Mitter, R.; Rosenthal, R.; et al. Tracking the Evolution of Non-Small-Cell Lung Cancer. N Engl J Med. 2017, 1, 2109-2121, doi: 10.1056/NEJMoa1616288.

41. Lengauer, C.; Kinzler, K.W.; Vogelstein, B. Genetic instabilities in human cancers. Nature. 1998, 17, 643-9, doi: $10.1038 / 25292$.

42. Curty, G.; de Carvalho, P.S.; Soares, M.A. The Role of the Cervicovaginal Microbiome on the Genesis and as a Biomarker of Premalignant Cervical Intraepithelial Neoplasia and Invasive Cervical Cancer. Int J Mol Sci. 2019, 28, 222, doi: 10.3390/ijms21010222.

43. Carter, S.L.; Cibulskis, K.; Helman, E.; McKenna, A.; Shen, H.; Zack, T.; Laird, P.W.; Onofrio, R.C.; Winckler, W.; Weir, B.A.; et al. Absolute quantification of somatic DNA alterations in human cancer. Nat Biotechnol. 2012, 30, 413-21. doi: 10.1038/nbt.2203.

44. Goh, J.Y.; Feng, M.; Wang, W.; Oguz, G.; Yatim, S.M.J.M.; Lee, P.L.; Bao, Y.; Lim, T.H.; Wang, P.; Tam, W.L.; et al. Chromosome 1q21.3 amplification is a trackable biomarker and actionable target for breast cancer recurrence. Nat Med. 2017, 23, 1319-1330, doi: 10.1038/nm.4405.

45. Turajlic, S.; Xu, H.; Litchfield, K.; Rowan, A.; Chambers, T.; Lopez, J.I.; Nicol, D.; O'Brien, T.; Larkin, J.; Horswell, S.; et al. Renal Consortium. Tracking Cancer Evolution Reveals Constrained Routes to Metastases: TRACERx Renal. Cell. 2018, 19, 581-594, doi: 10.1016/j.cell.2018.03.057.

46. Bielski, C.M.; Zehir, A.; Penson, A.V.; Donoghue, M.T.A.; Chatila, W.; Armenia, J.; Chang, M.T.; Schram, A.M.; Jonsson, P.; Bandlamudi, C.; et al. Genome doubling shapes the evolution and prognosis of advanced cancers. Nat Genet. 2018, 50, 1189-1195, doi: 10.1038/s41588-018-0165-1.

47. Taylor, A.M.; Shih, J.; Ha, G.; Gao, G.F.; Zhang, X.; Berger, A.C.; Schumacher, S.E.; Wang, C.; Hu, H.; Liu, J.; et al. Cancer Genome Atlas Research Network, Cherniack AD, Beroukhim R, Meyerson M. Genomic and Functional Approaches to Understanding Cancer Aneuploidy. Cancer Cell. 2018, 9, 676-689, doi: 10.1016/j.ccell.2018.03.007.

48. Bakhoum, S.F.; Kabeche, L.; Murnane, J.P.; Zaki, B.I.; Compton, D.A. DNA-damage response during mitosis induces whole-chromosome missegregation. Cancer Discov. 2014, 4, 1281-9. doi: 10.1158/2159-8290.

49. Lee, H.S.; Lee, N.C.; Kouprina, N.; Kim, J.H.; Kagansky, A.; Bates, S.; Trepel, J.B.; Pommier, Y.; Sackett, D.; Larionov, V. Effects of Anticancer Drugs on Chromosome Instability and New Clinical Implications for Tumor-Suppressing Therapies. Cancer Res. 2016, 15, 902-11, doi: 10.1158/0008-5472.CAN-15-1617. 
50. zur Hausen, H. Papillomaviruses in human cancers. Proc Assoc Am Physicians. 1999, 111, 581-7, doi: 10.1046/j.1525-1381.1999.99723.

51. Burd, E.M. Human papillomavirus and cervical cancer. Clin Microbiol Rev. 2003, 16, 1-17, doi: 10.1128/cmr.16.1.1-17.2003.

52. Kim, G.; Taye, J.; Yu, K.; Park, S.; Kim, J.; Kim, S.; Lee, D.; Wang, H.Y.; Park, K.H.; Lee, H. HPV E6/E7, hTERT, and Ki67 mRNA RT-qPCR Assay for Detecting High-Grade Cervical Lesion with Microscope Slides. Anal Cell Pathol (Amst). 2019, 14, 9365654, doi: 10.1155/2019/9365654.

53. Blackburn, E.H. Telomeres. Trends Biochem Sci. 1991, 16, 378-81, doi: 10.1016/0968-0004(91)90155-o.

54. Blasco, M.A.; Hahn, W.C. Evolving views of telomerase and cancer. Trends Cell Biol. 2003, 13, 289-94, doi: 10.1016/s0962-8924(03)00085-0.

55. Bateman, A.C.; Katundu, K.; Polepole, P.; Shibemba, A.; Mwanahamuntu, M.; Dittmer, D.P.; Parham, G.P.; Chibwesha, C.J. Identification of human papillomaviruses from formalin-fixed, paraffin-embedded pre-cancer and invasive cervical cancer specimens in Zambia: a cross-sectional study. Virol J. 2015, 16, 12:2, doi: 10.1186/s12985-014-0234-8.

56. Li, Y.; Zhang, M.C.; Xu, X.K.; Zhao, Y.; Mahanand, C.; Zhu, T.; Deng, H.; Nevo, E.; Du, J.Z.; Chen, X.Q. Functional Diversity of p53 in Human and Wild Animals. Front Endocrinol (Lausanne). 2019, 12, 152, doi: 10.3389/fendo.2019.00152.

57. Shaikh, M.F.; Morano, W.F.; Lee, J.; Gleeson, E.; Babcock, B.D.; Michl, J.; Sarafraz-Yazdi, E.; Pincus, M.R.; Bowne, W.B. Emerging Role of MDM2 as Target for Anti-Cancer Therapy: A Review. Ann Clin Lab Sci. 2016, 46, 627-634.

58. Yaginuma, Y.; Westphal, H. Analysis of the p53 gene in human uterine carcinoma cell lines. Cancer Res. 1991, 15, 6506-9.

59. Nicolas, M.; Wolfer, A.; Raj, K.; Kummer, J.A.; Mill, P.; van Noort, M.; Hui, C.C.; Clevers, H.; Dotto, G.P.; Radtke, F. Notch1 functions as a tumor suppressor in mouse skin. Nat Genet. 2003, 33, 416-21, doi: 10.1038/ng1099.

60. Rangarajan, A.; Talora, C.; Okuyama, R.; Nicolas, M.; Mammucari, C.; Oh, H.; Aster, J.C.; Krishna, S.; Metzger, D.; Chambon, P.; et al. Notch signaling is a direct determinant of keratinocyte growth arrest and entry into differentiation. EMBO J. 2001, 2, 3427-36, doi: 10.1093/emboj/20.13.3427.

61. Yugawa, T.; Handa, K.; Narisawa-Saito, M.; Ohno, S.; Fujita, M.; Kiyono, T. Regulation of Notch1 gene expression by 553 in epithelial cells. Mol Cell Biol. 2007, 27, 3732-42, doi: 10.1128/MCB.02119-06.

62. Narisawa-Saito, M.; Handa, K.; Yugawa, T.; Ohno, S.; Fujita, M.; Kiyono, T. HPV16 E6-mediated stabilization of ErbB2 in neoplastic transformation of human cervical keratinocytes. Oncogene. 2007, 10, 2988-96, doi: 10.1038/sj.onc.1210118.

63. Thomas, M.; Banks, L. Inhibition of Bak-induced apoptosis by HPV-18 E6. Oncogene. 1998, 10, 2943-54, doi: 10.1038/sj.onc.1202223.

64. Verlaat, W.; Van Leeuwen, R.W.; Novianti, P.W.; Schuuring, E.; Meijer, C.J.L.M.; Van Der Zee, A.G.J.; Snijders, P.J.F.; Heideman, D.A.M.; Steenbergen, R.D.M.; Wisman, G.B.A. Host-cell DNA methylation patterns during high-risk HPV-induced carcinogenesis reveal a heterogeneous nature of cervical pre-cancer. Epigenetics. 2018, 13, 769-778. doi: 10.1080/15592294.2018.1507197.

65. Lengauer, C.; Kinzler, K.W.; Vogelstein, B. Genetic instability in colorectal cancers. Nature. 1997, 10, 623-7, doi: $10.1038 / 386623 a 0$.

66. Cimini, D. Merotelic kinetochore orientation, aneuploidy, and cancer. Biochim Biophys Acta. 2008, 1786, 32-40, doi: 10.1016/j.bbcan.2008.05.003.

67. Siegel, E.M.; Riggs, B.M.; Delmas, A.L.; Koch, A.; Hakam, A.; Brown, K.D. Quantitative DNA methylation analysis of candidate genes in cervical cancer. PLoS One. 2015, 31, e0122495, doi: 10.1371/journal.pone.0122495.

68. Gu, Y.; Wan, C.; Qiu, J.; Cui, Y.; Jiang, T.; Zhuang, Z. Circulating HPV cDNA in the blood as a reliable biomarker for cervical cancer: A meta-analysis. PLoS One. 2020, 6, e0224001, doi: 10.1371/journal.pone.0224001.

69. Guo, X.; Hao, Y.; Kamilijiang, M.; Hasimu, A.; Yuan, J.; Wu, G.; Reyimu, H.; Kadeer, N.; Abudula, A. Potential predictive plasma biomarkers for cervical cancer by 2D-DIGE proteomics and Ingenuity Pathway Analysis. Tumour Biol. 2015, 36, 1711-20, doi: 10.1007/s13277-014-2772-5.

70. Yin, M.Z.; Tan, S.; Li, X.; Hou, Y.; Cao, G.; Li, K.; Kou, J.; Lou, G. Identification of phosphatidylcholine and lysophosphatidylcholine as novel biomarkers for cervical cancers in a prospective cohort study. Tumour Biol. 2016, 37, 5485-92, doi: 10.1007/s13277-015-4164-x. 
71. Godoy-Vitorino, F.; Ortiz-Morales, G.; Romaguera, J.; Sanchez, M.M.; Martinez-Ferrer, M.; Chorna, N. Discriminating high-risk cervical Human Papilloma Virus infections with urinary biomarkers via non-targeted GC-MS-based metabolomics. PLoS One. 2018, 28, e0209936, doi: 10.1371/journal.pone.0209936.

72. Longuespée, R.; Ly, A.; Casadonte, R.; Schwamborn, K.; Kazdal, D.; Zgorzelski, C.; Bollwein, C.; Kriegsmann, K.; Weichert, W.; Kriegsmann, J.; et al. Identification of MALDI Imaging Proteolytic Peptides Using LC-MS/MS-Based Biomarker Discovery Data: A Proof of Concept. Proteomics Clin Appl. 2019, 13, e1800158, doi: 10.1002/prca.201800158.

73. Zhu, H.; Zhu, H.; Tian, M.; Wang, D.; He, J.; Xu, T. DNA Methylation and Hydroxymethylation in Cervical Cancer: Diagnosis, Prognosis and Treatment. Front Genet. 2020, 9, 11:347, doi: 10.3389/fgene.2020.00347.

74. Kelly, H.; Benavente, Y.; Pavon, M.A.; De Sanjose, S.; Mayaud, P.; Lorincz, A.T. Performance of DNA methylation assays for detection of high-grade cervical intraepithelial neoplasia (CIN2+): a systematic review and meta-analysis. Br J Cancer. 2019, 121, 954-965, doi: 10.1038/s41416-019-0593-4.

75. Tornesello, M.L.; Faraonio, R.; Buonaguro, L.; Annunziata, C.; Starita, N.; Cerasuolo, A.; Pezzuto, F.; Tornesello, A.L.; Buonaguro, F.M. The Role of microRNAs, Long Non-coding RNAs, and Circular RNAs in Cervical Cancer. Front Oncol. 2020, 20, 150, doi: 10.3389/fonc.2020.00150.

76. Bergman, H.; Buckley, B.S.; Villanueva, G.; Petkovic, J.; Garritty, C.; Lutje, V.; Riveros-Balta, A.X.; Low, N.; Henschke, N. Comparison of different human papillomavirus (HPV) vaccine types and dose schedules for prevention of HPV-related disease in females and males. Cochrane Database Syst Rev. 2019, 22, CD013479, doi: 10.1002/14651858.CD013479.

77. Bowden, S.J.; Kalliala, I.; Veroniki, A.A.; Arbyn, M.; Mitra, A.; Lathouras, K.; Mirabello, L.; Chadeau-Hyam, M.; Paraskevaidis, E.; Flanagan, J.M.; et al. The use of human papillomavirus DNA methylation in cervical intraepithelial neoplasia: A systematic review and meta-analysis. EBioMedicine. 2019, 50, 246-259, doi: 10.1016/j.ebiom.2019.10.053. 